\title{
Paralelo entre planejamentos de atividades presenciais e remotas na formação inicial de professores de química envolvendo a conservação e restauração de bens culturais
}

\author{
Parallel between the planning of presential and remote activities in the chemistry \\ teachers' initial training integrating the conservation and restoration of cultural assets \\ Paralelismo entre los planes de actividades presenciales y remotos en la formación \\ inicial de profesores de química que impliquen la conservación y restauración de bienes \\ culturales
}

Matheus de Castro e Silva ${ }^{1}$

Penha Souza Silva ${ }^{2}$

\section{Resumo}

A inclusão das Tecnologias de Informação e Comunicação (TIC) nas licenciaturas ocorreu como forma de possibilitar um ensino superior remoto em diferentes instituições e universidades. Essa inclusão fez com que os planejamentos das disciplinas fossem alterados, de modo a transpor atividades presenciais em práticas assíncronas e encontros síncronos. Neste relato de experiências, discutimos de que forma o planejamento de um conjunto de atividades de formação inicial de professores de Química e licenciandos em Pedagogia foi modificado para o ensino remoto, contemplando as TIC e suas potencialidades. Inicialmente, apresentamos um panorama do contexto pandêmico e das políticas de ensino remoto emergencial da Universidade Federal de Minas Gerais (UFMG) - local onde ocorreu a coleta de dados a partir de uma disciplina optativa com a participação de dezoito licenciandos. A partir da participação desses licenciandos em atividades assíncronas e encontros síncronos, percebemos as possibilidades de cada TIC para a formação inicial de professores. Ademais, fazendo um paralelo entre os planos presenciais e remotos, destacamos a perda de aspectos investigativos das atividades e a necessidade de estudos envolvendo propostas curriculares envolvendo ensino remoto, TIC e contextos investigativos na formação de professores. Palavras-chave: TIC; planejamento didático; conservação de bens culturais; formação de professores; ensino remoto.

\begin{abstract}
The Information and Communication Technologies (ICT) access in undergraduated courses is a way of enabling remote higher education in different institutions and universities. This process changes the disciplines' didactic plans, in order to transpose face-to-face activities into asynchronous practices and synchronous meetings. In this paper, we discuss how the

\footnotetext{
${ }^{1}$ Mestre em Educação, PROMESTRE - Mestrado Profissional em Educação e Docência, Universidade Federal de Minas Gerais, Belo Horizonte, Minas Gerais, Brasil. matheuscastroqui@gmail.com. Currículo Lattes: http://lattes.cnpq.br/1524304388085935. E-mail: matheuscastroqui@gmail.com ORCID: https://orcid.org/00000003-4256-6320

2 Doutora em Educação, Departamento de Métodos e Técnicas de Ensino, Faculdade de Educação, Universidade Federal de Minas Gerais, Belo Horizonte, Minas Gerais, Brasil. penhadss@gmail.com. Currículo Lattes: http://lattes.cnpq.br/8502422679229022. E-mail: penhadss@gmail.com ORCID: https://orcid.org/0000$\underline{0001-5737-9566}$
} 
planning of a set of initial training activities for Chemistry teachers and Pedagogy undergraduates was modified for remote education, contemplating ICT and its potential. Initially, we present an overview of the pandemic context and emergency remote teaching policies at the Universidade Federal de Minas Gerais (UFMG) - where data were collected from a discipline in which eighteen undergraduates participated. From the participation of these undergraduates in asynchronous activities and synchronous meetings, we realized the possibilities of each ICT for the initial training of teachers. Furthermore, making a parallel between the presential and remote plans, we highlight the loss of investigative aspects of the activities and the need for studies involving curricular proposals involving remote teaching, ICT and investigative contexts in teacher education.

Keywords: ICT; didactic planning; cultural assets conservation; teacher training; remote learning.

\section{Resumen}

La inclusión de las Tecnologías de la Información y la Comunicación (TIC) en las titulaciones fue una forma de posibilitar la educación superior remota en diferentes instituciones y universidades. Esta inclusión hizo cambiar los planes de las disciplinas, con el fin de transponer las actividades presenciales en prácticas asincrónicas y reuniones sincrónicas. En este relato de experiencia se comenta cómo se modificó la planificación de un conjunto de actividades de formación inicial para profesores de Química y licenciados en Pedagogía para la educación a distancia, contemplando las TIC y sus potencialidades. Inicialmente, presentamos un panorama general del contexto de la pandemia y las políticas de enseñanza remota de emergencia en la Universidade Federal de Minas Gerais (UFMG), donde se realizó la recolección de datos de una asignatura optativa con la participación de dieciocho estudiantes universitarios. A partir de la participación de estos estudiantes en actividades asincrónicas y reuniones sincrónicas, nos dimos cuenta de las posibilidades de cada TIC para la formación inicial de los docentes. Además, haciendo un paralelismo entre los planes presencial y remoto, destacamos la pérdida de aspectos investigativos de las actividades y la necesidad de estudios sobre propuestas curriculares que involucren la enseñanza a distancia, las TIC y los contextos investigativos en la formación del profesorado.

Palabras llave: TIC; planificación didáctica; conservación de bienes culturales; formación de profesores; enseñanza a distancia.

\section{Introdução}

O surto de COVID-19 impactou diversas áreas da vida humana, assim como suas instituições e práticas, como as universidades públicas e o processo de formação inicial de professores. Neste contexto, essas entidades acadêmicas foram obrigadas a alterar o ensino presencial para um formato remoto ou híbrido, neste caso, respeitando as regras de distanciamento social e protocolos de higienização e proteção pessoal. Segundo Lago et al. (2021), a pandemia de Sars-CoV-2 levou o corpo docente universitário a reformular suas atividades e discutir a inserção das Tecnologias de Informação e Comunicação (TIC) em seus 
planejamentos, acarretando, assim, possibilidades para um ensino remoto emergencial (ERE). Esse formato de ensino compreende alguns desafios tais como a ausência ou precariedade de infraestrutura de rede - realidade de 155 mil estudantes de cursos de graduação, no Brasil, em 2018, segundo CASTIONI et al. (2021) -, a baixa adesão e participação dos estudantes aos momentos síncronos, a falta de domínio de recursos digitais para aprender ou ensinar remotamente e a sobrecarga de atividades (AMARAL; POLYDORO, 2020). Além desses obstáculos, o corpo docente das universidades teve que lidar com mais uma empreitada educacional: alterar os planos pedagógicos das atividades presenciais para o ensino remoto emergencial (ERE). Inicialmente, acreditamos ser necessário definir o que é esse formato e como ele se difere de outras propostas remotas de ensino, como a Educação a Distância $(\mathrm{EaD})$.

Segundo Amaral e Polydoro (2020), o ERE contempla soluções temporárias e remotas que atuam na manutenção ou construção de interações educacionais síncronas e assíncronas. Esse formato não se caracteriza pela simples transposição das atividades presenciais para o ambiente virtual e se difere da Educação a Distância (EaD), visto que não é apoiada em um planejamento predefinido e por atividades totalmente imersivas e assíncronas assistidas por um ambiente virtual. Essas diferenças nem sempre são entendidas pelas instituições educacionais de ensino superior, visto que algumas "têm implementado respostas rápidas que envolvem equivocadamente as tecnologias como se fossem experiências de EaD” (ARRUDA, 2020). Assim, torna-se necessário enfatizar que a Educação a Distância é uma

modalidade educacional na qual a mediação didático-pedagógica nos processos de ensino e aprendizagem ocorra com a utilização de meios e tecnologias de informação e comunicação, com pessoal qualificado, com políticas de acesso, com acompanhamento e avaliação compatíveis, entre outros, e desenvolva atividades educativas por estudantes e profissionais da educação que estejam em lugares e tempos diversos (BRASIL, 2017, p. 3).

Seja no ensino remoto ou na Educação a Distância, as Tecnologias de Informação e comunicação ou Tecnologias Digitais de Informação e Comunicação (TDIC) se constituem como um recurso essencial, que se integram tanto às atividades de ensino, como aos planos pedagógicos. As Tecnologias de Informação e Comunicação envolvem as tecnologias analógicas, como o livro, o quadro negro, os materiais impressos em máquinas de xerox, enquanto, segundo Arruda (2020), as Tecnologias Digitais de Informação e Comunicação já demandam um suporte eletrônico, com um aplicativo ou um software, sem análogo material, 
como uma apresentação em PowerPoint, um vídeo arquivado em um computador etc. Neste trabalho, iremos optar pelo primeiro termo, entendendo que as TIC também podem ser digitais. Pensando nesse contexto educacional, Kenski (2012) discute que as Tecnologias de Informação e Comunicação

não são o objeto, nem a sua substância, nem sua finalidade. Elas estão presentes em todos os momentos do processo pedagógico, desde o planejamento das disciplinas, a elaboração da proposta curricular até a certificação dos alunos que concluíram um curso. a presença de determinada tecnologia pode induzir profundas mudanças na maneira de organizar o ensino [...] A escolha de determinado tipo de tecnologia altera profundamente a natureza do processo educacional e a comunicação entre os participantes (KENSKI, 2012, p. 44-5).

Desta forma, as TIC, na área da Educação, podem ser entendidas como recursos para dirimir o afastamento entre os atores do processo de ensino-aprendizagem em atividades de ensino e aprendizagem remotas. Elas permitem a utilização de multimídias e ferramentas de interação à distância, possibilitando o acesso a um grande número de informações, permitindo a interação e a colaboração entre pessoas distantes geograficamente ou inseridas em contextos diferenciados. O diferencial de uma TIC para um quadro negro, por exemplo, consiste na integração entre diferentes recursos tecnológicos provenientes da informática, como os softwares. Desta forma, as TIC podem ser vistas como um imperativo para a área da Educação, contudo algumas considerações devem ser apresentadas, especialmente para os recursos tecnológicos digitais que as integram.

A priori, Vivanco e Gorostiaga (2017) apontam que as TIC e a área da Educação correspondem a núcleos culturais distintos, o que obstaculiza diálogos entre elas. Os autores destacam que a dificuldade de implementação dessas tecnologias nas atividades de ensino e aprendizagem deve ser entendida a partir dessa relação conflituosa, na qual há a "implantação" na Educação de elementos que lhe são estranhos, "já que não surgem ou desenvolvem-se em seu meio" (VIVANCO, GOROSTIAGA, 2017). Além disso, podemos destacar que as TIC no processo formativo docente no ensino remoto suscitam a máxima de que o professor deve ter habilidade em diversos softwares e programas, pois esse seria o "futuro da Educação". Nesse sentido, acreditamos que 
[...] a formação docente não significa adquirir um elenco de 'destrezas' necessárias à prática pedagógica mais atual, mas sim propor experiências inovadoras de utilização de tecnologias para a construção de conhecimentos. [...] O que significa conceber as tecnologias como meio, linguagem, sem nos esquecermos de considerá-las objetos de estudo e reflexão (ARAÚJO, SILVA, 2016, p. 74)

Desta forma, esperamos com este trabalho, colocando as TIC como objetos de estudo, discutir o percurso de atividades de formação inicial de dezesseis licenciandos em Química e dois cursistas em Pedagogia em um conjunto de atividades de uma disciplina remota envolvendo a integração entre Arte e Ciências, a partir da conservação e restauração de bens

culturais. É importante ressaltar que, inicialmente, essa disciplina seria ofertada no formato presencial, alterado devido à pandemia. Assim, procuramos discutir neste trabalho de que forma as TIC podem auxiliar na transição das atividades de uma disciplina de formação inicial de professores no ensino presencial para o formato remoto. Para isso, dispomos este trabalho em seções nas quais destacamos o contexto da pesquisa e das políticas educacionais propostas pela Universidade Federal de Minas Gerais (UFMG) - instituição onde ocorreu a oferta da disciplina -, os caminhos metodológicos escolhidos e a utilização das TIC como ferramenta de um material didático e, também, de construção de conhecimento com os licenciandos em encontros síncronos.

\section{Contexto da pesquisa e o enfrentamento da pandemia de COVID-19 pela Universidade} Federal de Minas Gerais

Para discutir a forma como ocorreu a transição do ensino presencial para o remoto, é importante, inicialmente, deflagrar a maneira como as autoridades da Universidade Federal de Minas Gerais lidaram com o impacto da pandemia, contextualizando, assim, este trabalho. Em 18 de março de 2020, houve a suspensão das atividades acadêmicas (ensino, pesquisa e extensão) na UFMG, segundo a Portaria nº 1819. Essa suspensão foi justificada pela ausência de acesso à internet, a equipamentos e/ou a um letramento digital necessário que permitissem as atividades remotas tanto dos estudantes quanto dos professores (ANDIFES, 2020), corroborando as medidas sugeridas pelo Fórum de Dirigentes das Instituições Públicas de Ensino Superior de Minas Gerais (Foripes-MG). Quatro meses após a publicação da Portaria $\mathrm{n}^{\circ}$ 1819, em 09 de julho de 2020, o Conselho de Ensino, Pesquisa e Extensão (Cepe) da UFMG promulga a Resolução $n^{\circ}$ 02/2020 que "regulamenta o ensino remoto emergencial para os cursos de graduação da UFMG durante período de pandemia da doença COVID-19" 


\section{ODEVIR EDUCAÇÃO}

ISSN: 2526-849X

(UFMG, 2020), considerando a Portaria do MEC no 544 de 16 de junho de 2020 - na qual sugere a substituição das aulas presenciais por aulas em meios digitais, enquanto durar a situação de pandemia no novo coronavírus - e a Medida Provisória n 934, de 10 de abril de 2020 - que estabelece normas excepcionais sobre o ano letivo da educação básica e do ensino superior.

Segundo essa Resolução, o ensino remoto emergencial (ERE) seria o formato temporário das atividades curriculares de ensino e das ações pedagógicas da UFMG, no contexto pandêmico, com a utilização das "tecnologias digitais de informação e comunicação, possibilitando a interação estudante-docente-conhecimento" (UFMG, 2020). Além disso, o documento discute as funções de cada órgão colegiado no ERE, cabendo às Câmeras de Graduação definir

as diretrizes sobre estratégias de ensino-aprendizagem, de uso de tecnologias digitais de informação e comunicação e de ambientes virtuais de aprendizagem, de processos avaliativos e acompanhamento, de distribuição de carga horária e de aferição de assiduidade para a realização das atividades remotas (UFMG, 2020, p. 2).

O corpo docente da Universidade, segundo o documento, deveria se adequar a esse formato, disponibilizando um plano de ensino no ambiente virtual de aprendizagem (AVA) o Moodle - até a primeira semana das aulas no formato remoto emergencial. Ademais, os professores de graduação e pós-graduação deveriam priorizar as atividades assíncronas nos mesmos horários da disciplina presencial e ofertar, preferencialmente, uma atividade síncrona para cada 15 horas-aula com o uso da plataforma Microsoft Teams.

A demanda pelo uso dessas plataformas implicou algumas iniciativas de letramento digital dos estudantes e professores, como a criação do programa "Integração Docente: Ações Formativas para as Práticas Pedagógicas", unindo diversos órgãos da UFMG. Criado em abril de 2020 e oficialmente lançado em 10 de junho de 2020, com o objetivo de discutir o planejamento do retorno às atividades letivas em tempos de pandemia, foi oferecido aos docentes, na página do programa fóruns, oficinas, cursos, webinars e outras ações virtuais de apoio no uso de tecnologias digitais no ensino. Por exemplo, há tutoriais e guias sobre acessibilidade no ensino remoto emergencial e sobre o uso do Microsoft Office 365 e Teams - serviços disponíveis aos membros da comunidade por meio da plataforma minhaUFMG, 


\section{OO DEVIR EDUCAÇÃO}

ISSN: 2526-849X

tutoriais sobre a produção e a publicação de videoaulas utilizando o PowerPoint e sobre a utilização do Moodle. A partir dessas ações, o ensino remoto emergencial teve início, na UFMG, em 03 de agosto de 2020, data correspondente ao primeiro período letivo de 2020.

\section{Procedimentos metodológicos}

Os dados deste trabalho foram coletados na primeira quinzena de outubro de 2020 a partir da participação de dezoito estudantes da Universidade Federal de Minas Gerais (UFMG), sendo dezesseis deles cursando a licenciatura em Química e, os demais, o curso de Pedagogia. Esses licenciandos estavam matriculados em uma disciplina optativa de 30 horas denominada "Ateliê de Ciências" cujo planejamento preconizava o contato dos estudantes com obras e técnicas artísticas como contextualização no ensino de Ciências, especialmente a Química. Desta forma, este trabalho traz um recorte dos dados coletados durante as atividades da disciplina, obtidos a partir de atividades ofertadas no primeiro semestre de 2020, que, devido à pandemia de Covid-19, ocorreu entre 05 de agosto e 27 de novembro. Essa disciplina contou com encontros síncronos na plataforma Microsft Teams, que foram registrados com o uso do software OBS Studio, e atividades assíncronas, as quais foram desenvolvidas pelos licenciandos em suas casas, utilizando o Moodle. O uso dessa plataforma assim como de outros softwares e programas está apresentado e discutido na seção Resultados. Além disso, uma entrevista foi realizada, em 03 de julho de 2020, com um membro docente da Universidade - o professor Dr. João Cura D’Ars de Figueiredo Junior para construir um material didático para a disciplina. Todas as produções orais e escritas dos licenciandos, assim como as imagens produzidas na entrevista, foram coletadas mediante assinatura do Termo de Consentimento Livre e Esclarecido (TCLE) pelos participantes.

Consideramos este trabalho um relato de experiências, visto que é uma forma narrativa de acontecimentos em diálogo com informações teóricas. Acreditamos que a forma como cada Tecnologia de Informação e Comunicação foi se integrando ao planejamento e ao desenvolvimento das atividades da disciplina perfazem resultados deste relato.

A partir das informações apresentadas anteriormente e cientes de que a maneira como uma pesquisa é construída relaciona-se intimamente com os dados coletados e sua análise, 


\section{OD DEVIR EDUCAÇÃO \\ ISSN: 2526-849X}

acreditamos que este trabalho se configura como uma pesquisa-ação. Essa pesquisa pode ser definida como a investigação voltada para a "resolução de problemáticas específicas do contexto da educação [...], concebendo condições aos profissionais dessa área e, possibilidades de ampliação nos modos de fazer, já existentes, ou criando novas formas, estratégias e inovações" (HETKOWSKI, 2018).

\section{Resultados e discussões}

\section{Transitando das atividades presenciais para o ensino remoto emergencial}

A princípio, iremos discutir a maneira pela qual dois conjuntos de atividades da disciplina optativa foram planejados em um contexto presencial. Logo após, apresentaremos sua transição para o ensino remoto. É importante ressaltar que o planejamento presencial das atividades contém possibilidades da abordagem de temas e do que era esperado nas discussões em sala de aula.

A atividade presencial foi planejada a partir da discussão de dois processos de deterioração de bens culturais: o craquelê ou craquelure de pinturas a óleo e a corrosão de bens culturais em metais expostos em ambientes abertos. O craquelê são fraturas na superfície da obra, formadas a partir da fragilidade das camadas de tinta e pela movimentação do suporte, geralmente em tecido, da tela (FIGUEIREDO JÚNIOR, 2012). Aos licenciandos, seriam apresentadas fotografias de algumas pinturas, como a Figura 1, como um percurso inicial para a investigação dos fenômenos que poderiam ter levado à produção dos craquelês. 


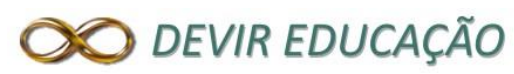

ISSN: 2526-849X

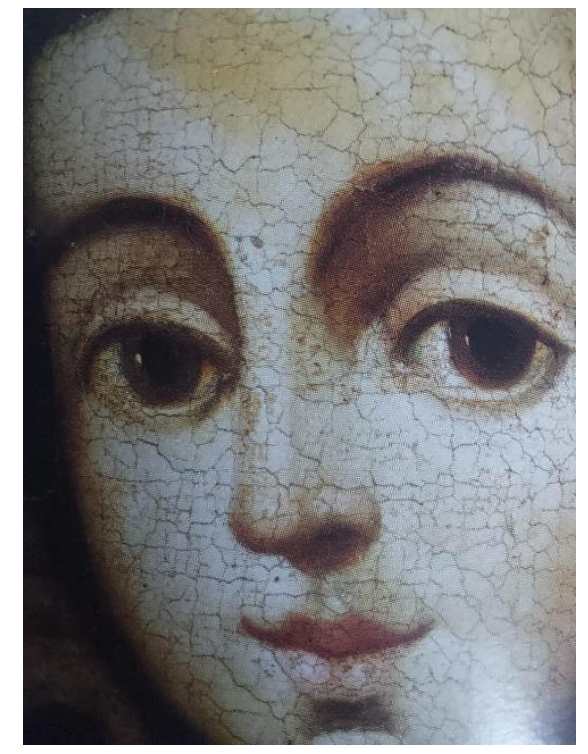

Figura 1: Detalhe de pintura a óleo com craquele. Fonte: Pascual, Patiño (2003, p. 36).

A partir da apresentação de imagens dessas obras, os licenciandos, divididos em grupos, seriam convidados a discutir e registrar as causas da deterioração. Essa deterioração integra as reações de polimerização e o processo de secagem que o óleo da tinta sofre ao longo do tempo. A oxidação das moléculas de óleo produz um polímero com pouca liberdade de movimentação, tornando a superfície da pintura rígida e quebradiça, formando então o craquelê (FIGUEIREDO JUNIOR, 2012). Os contínuos movimentos do tecido da tela, assim como variações de temperatura, podem agravar essa deterioração (PASCUAL, PATIÑO, 2003).

É importante ressaltar que os licenciandos não teriam que construir uma "resposta correta" baseada nas informações discutidas, mas, a partir dessa atividade, eles seriam instigados a discutir em sala de aula sobre o material da obra e sua relação com os conteúdos científicos. Desta forma, haveria o registro em vídeo dessas discussões, a fim de perceber como os licenciandos investigariam o problema proposto a partir dos conhecimentos de Química que já possuíam e que poderiam ser pesquisados por eles em contraponto com o contexto da conservação e do restauro. 


\section{OO DEVIR EDUCAÇÃO \\ ISSN: 2526-849X}

As atividades sobre a corrosão de bens culturais em metal seriam iniciadas a partir da visualização in loco, pelos licenciandos, da obra de Leandro Gabriel ${ }^{3}$ (Figura 2), presente no jardim externo da Faculdade de Educação da UFMG, local onde ocorreriam as aulas da disciplina.

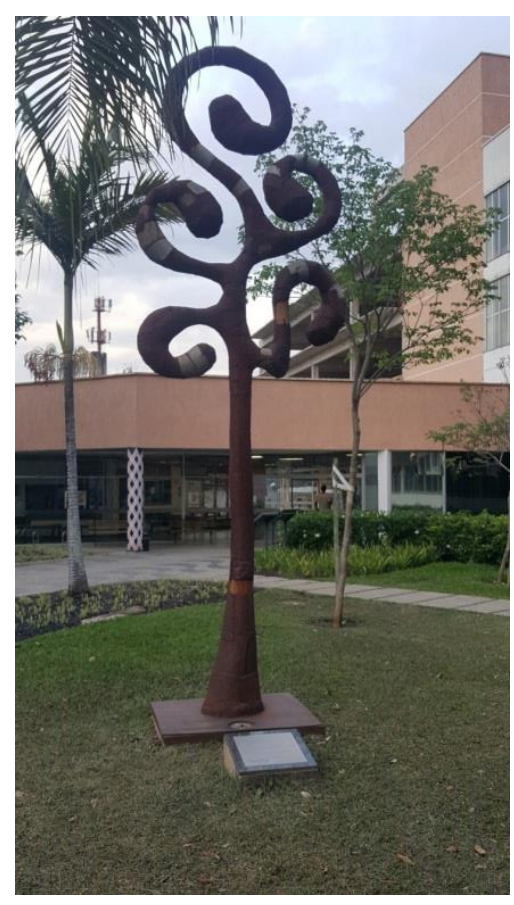

Figura 2: Leandro Gabriel, Sem título, 2005.

Dos autores (2021).

Aos licenciandos, seria sugerido fotografar a escultura de Leandro Gabriel para que construíssem um conjunto de imagens que embasassem suas investigações e discussões sobre os processos químicos que promoveram o aspecto visual da obra. Os licenciandos poderiam investigar a composição dos materiais da escultura, formada por aço corten ${ }^{4}$ e sucatas de metal, susceptíveis à corrosão. Assim, os estudantes seriam convidados a citar os fatores ambientais que possibilitariam esse tipo de deterioração, para proporem uma técnica para conservação e/ou restauração das obras sob efeito da corrosão. Desta forma, esperava-se que o entendimento do processo de corrosão - definido como "a deterioração de um material,

\footnotetext{
${ }^{3}$ Leandro Gabriel (1970 - hoje) é um artista mineiro, formado em Educação Artística pela Escola Grignard e desenvolve atualmente trabalhos com transformação da sucata de ferro e outros materiais metálicos.

${ }^{4} \mathrm{O}$ aço corten é um tipo de material metálico com coloração marrom-avermelhada, muito utilizado na construção civil e nas obras artísticas expostas em ambientes abertos, sob o efeito da umidade e luz solar.
} 


\section{OO DEVIR EDUCAÇÃO}

ISSN: 2526-849X

geralmente metálico, por ação química ou eletroquímica do meio ambiente associada ou não a esforços mecânicos" (GENTIL, 2014, p. 01) - e sua associação com as obras estudadas permitiriam soluções científicas para a perpetuação do patrimônio cultural.

Essas atividades ocorreriam em dois encontros presenciais de 1:40 hora cada, impossibilitados pelo fechamento das unidades de ensino da UFMG em 18 de março de 2020. A partir disso, o formato desses conjuntos de atividades foi reformulado, baseado no ensino remoto emergencial e nas possibilidades das Tecnologias de Informação e Comunicação, situadas, prioritariamente, na plataforma Moodle e no Microsoft Teams.

É importante ressaltar que as atividades presenciais tinham um caráter investigativo, na qual os licenciandos poderiam discutir alguns aspectos dos fenômenos que levariam à deterioração de bens culturais em dois diferentes suportes - tela e metal. A Química e as demais Ciências Naturais poderiam ser ferramentas para a restauração material desses bens culturais, contudo deveria haver o entendimento, por parte dos licenciandos, dessa relação. Pensando em como trazer essa proposta para o ensino remoto, o Dr. João Cura D'Ars de Figueiredo Júnior, professor associado do Departamento de Artes Plásticas da Escola de Belas Artes da UFMG, foi convidado para uma entrevista. A escolha deste professor é justificada pela sua formação em Química - graduação, mestrado, doutorado e pós-doutorado - e a sua atuação na pesquisa de conservação e restauração de bens culturais. A entrevista foi gravada a fim de produzir um material para um conjunto de atividades envolvendo a conservação e a restauração, que seria vista, posteriormente, pelos licenciandos. Esse material seria, então, o ponto inicial das discussões, que ocorreram mediante as TIC, visto que os estudantes não puderam visualizar a obra de Leandro Gabriel in loco e nem serem reunidos em grupos presenciais para uma investigação em sala de aula. Esperávamos possibilitar aos licenciandos uma experiência remota tão rica quanto nos encontros presenciais, por isso houve a realização da entrevista.

A entrevista ocorreu remotamente em 03 de julho de 2020, aproximando-se de um formato semiestruturado, no qual havia um roteiro previamente definido com perguntas principais que foram complementadas por questões inerentes às circunstâncias momentâneas da coleta de informações (BONI, QUARESMA, 2005). Ressaltamos, aqui, a importância das TIC e dos programas na realização dessa entrevista, visto que ela foi realizada na plataforma 
do Google Meet e gravada utilizando o software Open Broadcaster Software, também conhecido por OBS Studio.

O Google Meet é um serviço gratuito lançado em 2017 que permite uma videochamada com tempo ilimitado entre diversas pessoas. Esse serviço conta com a geração de um link que pode ser enviado previamente aos participantes, direcionando-os a uma sala virtual. A interface dessa sala é formada por uma tela principal, no qual é possível visualizar os participantes da videochamada por meio de suas webcams, e um chat, onde é possível compartilhar arquivos e digitar informações que podem ser lidas por todos. Já o OBS Studio é um programa gratuito que pode ser obtido no site de seu desenvolvedor (OBS Project) que possui, dentre diversos usos, a funcionalidade de gravar a tela do computador e todas as ações que nela ocorre com som, produzindo arquivos no formato MPEG-4 Part 14 (Mp4). Esse formato permitiu a postagem da gravação da entrevista em uma plataforma de compartilhamento de vídeos denominada YouTube. Essa estratégia foi utilizada visto que os cinco arquivos da gravação da entrevista possuíam tamanhos acima de 150 megabytes. Pensando em um contexto pandêmico, no qual os licenciados devem possuir uma internet de qualidade durante suas experiências de formação síncronas e assíncronas, seria mais conveniente que eles assistissem ao vídeo em uma plataforma do que baixassem o arquivo, demandando uma quantidade de dados considerável. Desta forma, pensar na forma de produção de um material de formação docente envolve também considerar seu acesso e as condições digitais dos estudantes.

Além disso, as TIC foram utilizadas a fim de potencializar o contato dos licenciandos às integrações entre os conhecimentos científicos e as áreas de conservação e restauração por meio da entrevista realizada. Alguns trechos dessa entrevista serão reproduzidos nesse trabalho, para embasar as discussões realizadas pelos licenciandos em um fórum na plataforma Moodle (Figura 3). 


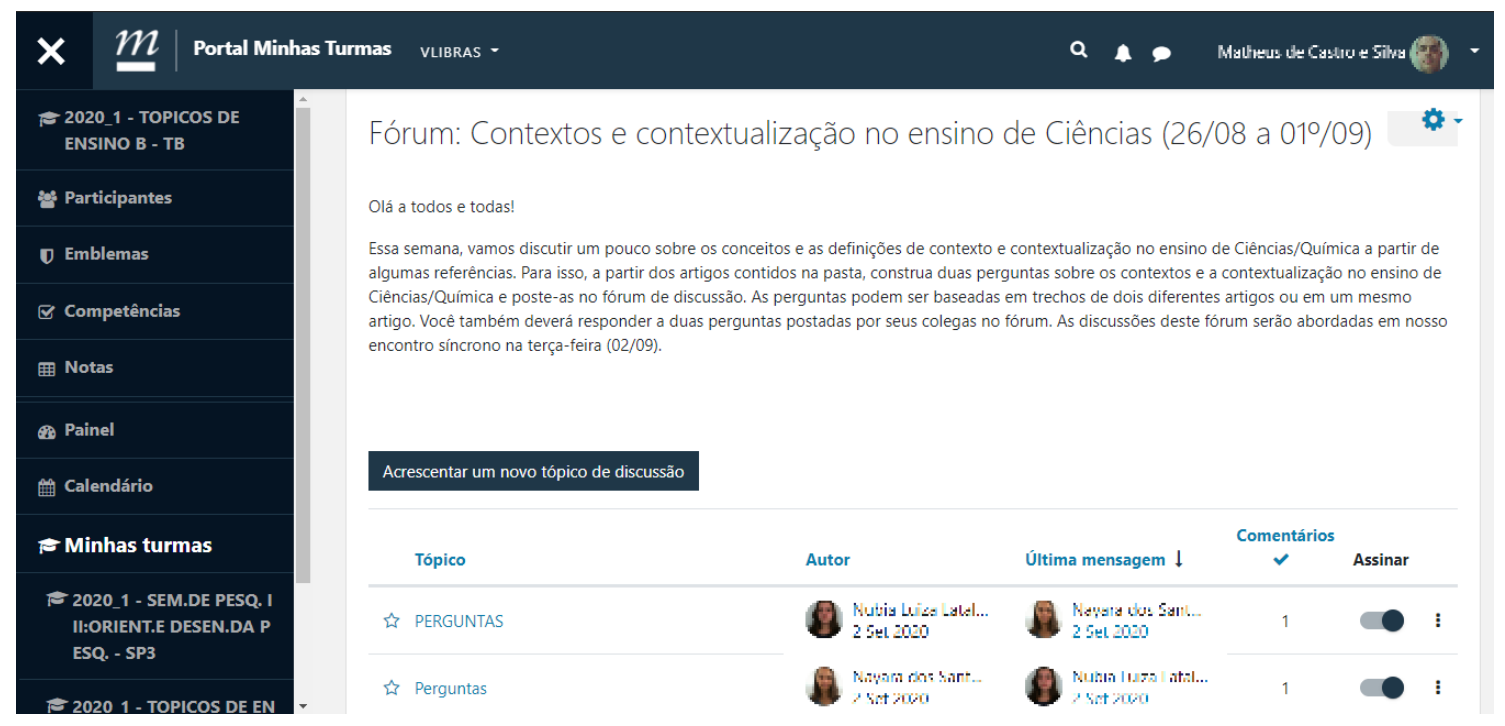

Figura 3: Interface do fórum da plataforma Moodle. Fonte: Autores (2021).

O Moodle (Modular Object-Oriented Dynamic Learning Environment) é um software de apoio a aprendizagem constituído por um ambiente virtual e seus recursos. Uma desses recursos são os Fóruns, nos quais os envolvidos em uma discussão podem postar suas contribuições em links, conforme representado na Figura 3. Todos os participantes com acesso a esse fórum podem ler e responder às contribuições dos demais, oportunizando uma interação assíncrona.

Nesse fórum, foi solicitado aos estudantes que, no período de primeiro de outubro a 07 de outubro de 2020, após assistirem 30 minutos da entrevista postada no YouTube, apontassem aspectos que eles teriam considerado mais relevante na integração entre Química/Ciências e a conservação e o restauro do patrimônio material. No último dia do prazo para a participação no fórum, ocorreria um encontro síncrono na plataforma Microsoft Teams para discussão dos tópicos levantados no fórum. A visualização de uma das telas dessa plataforma está representada na Figura 4. 


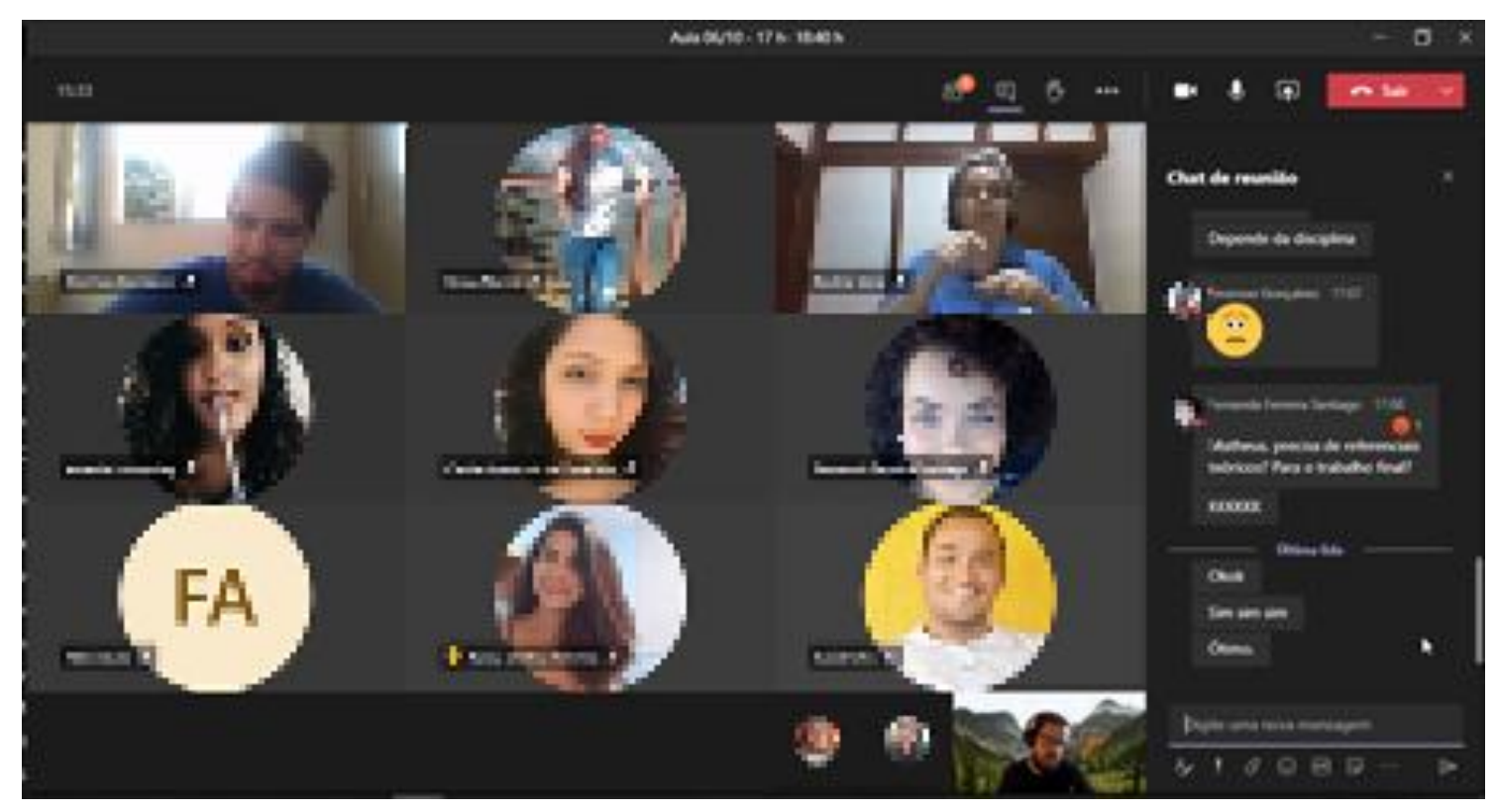

Figura 4: Interface da tela da plataforma Microsoft Teams. Fonte: Autores (2021).

O Microsoft Teams foi a plataforma escolhida pela UFMG para permitir a comunicação síncrona e assíncrona entre estudantes e professores por meio de videoconferência, chat (lado direito da Figura 4) e armazenamento de arquivos. Neste trabalho, essa plataforma foi utilizada apenas como software para encontros síncronos, onde os licenciandos participavam falando com o uso de microfone ou escrevendo suas contribuições no chat, de maneira análoga ao funcionamento do Google Meet. Foram selecionadas algumas falas e escritas que foram transcritas para este trabalho para discutirmos a percepção desses licenciandos sobre a integração entre Arte e Ciências pelas áreas da conservação e restauração.

\section{Participação dos licenciandos no fórum}

Inicialmente, trazemos nessa seção os trechos transcritos da entrevista com o professor Dr. João Cura que embasaram as participações dos licenciandos no fórum. Como não é um dos objetivos desse trabalho a transcrição integral da entrevista, optamos por selecionar seus pontos mais importantes, baseados nas discussões realizadas pelos estudantes. A transcrição 
dos trechos presentes no Quadro 1 foi feita sem o auxílio de programas, apenas visualizando a gravação da entrevista e passando as informações para a linguagem escrita. Para este trabalho, optamos por reformular algumas partes da transcrição de modo a aproximá-las da norma padrão da língua, sem, contudo, alterar seu conteúdo ou o encadeamento de ideias.

Quadro 1: Trechos da entrevista com o professor Dr. João Cura D’Ars de Figueiredo Junior

Entrevistador - Primeiramente, eu gostaria que o senhor falasse um pouco sobre quais são as diferenças entre as áreas de conservação e restauração e o que cada uma estuda. O objeto de estudo delas é o mesmo ou não?

Prof. Dr. João - Bom, a conservação e a restauração trabalham com a obra de arte. A diferença entre elas principalmente vai ser em como cada uma vai abordar a obra de arte. A gente fala que a restauração é todo procedimento que interfere diretamente na obra de arte. [...] A conservação interfere no entorno da obra de arte. [...] Então a gente pode falar, a grosso modo: o restaurador interfere diretamente na obra de arte, o conservador interfere no ambiente em torno da obra de arte para que ela não sofra reações de deterioração. Contudo, é difícil você simplesmente só conservar ou você só restaurar, porque não adianta você restaurar uma obra e, por exemplo, você levar para uma igreja e ela ter uma alta umidade lá dentro. Quer dizer, assim que você termina de restaurar a obra, ela vai começar a sofrer danos com essa umidade alta, então normalmente o profissional se forma nos dois campos: se forma tanto restaurador quanto conservador.

Entrevistador - Dentro do percurso formativo desse profissional, tem alguma relação com os conteúdos da Química? Eu gostaria que o senhor falasse se existe Química e, se sim, onde que ela auxilia. Quais são os fundamentos da Química e da Ciência que ajudariam esse profissional da conservação e da restauração? 
Prof. Dr. João - Tem um teórico da restauração que se chama Cesare Brandi ${ }^{5}$ que estudou a obra por vários aspectos. Então, ele fala que haveria três aspectos principais para a obra de arte: o primeiro seria o aspecto estético, que seria a beleza da obra, como você enxerga essa obra, se ela te agrada ou não; teria o aspecto histórico, então se a gente for observar, por exemplo, uma escultura do Barroco, podemos compreender muito sobre daquele período histórico por ela. Se a gente pega um prédio que foi construído na Idade Média ele vai também trazer muita informação, sobre temas relacionados com um período histórico específico. Assim, a estética é o primeiro aspecto, histórico é o segundo e o terceiro é a questão do material, por que queira ou não, toda obra de arte possui. Toda obra não, mas na maioria, como pintura, escultura, elas vão ser formadas por um material. Por exemplo, uma escultura feita em mármore, uma pintura que vai usar uma tinta que tem o pigmento e o aglutinante orgânico. Então, quando o Brandi fala que na área de restauração você tem que olhar a estética e a história, você não pode esquecer também que tem uma parte material ali presente. $\mathrm{O}$ restaurador tem que entender que quando for usar algum material específico numa obra de arte, ele tem que conhecer a Química daquele material. Um exemplo simples: se você pegar uma escultura em madeira, vamos imaginar que a escultura cai e o braço quebra e você tem que colocar um adesivo nela. Você tem que pensar o seguinte: “olha, posso usar o epóxi porque ele é uma cola muito forte e vai manter essa madeira no lugar". Mas dependendo do epóxi que você utilizar, o que que vai acontecer? Esse epóxi vai ser muito rígido e a madeira tem um movimento natural de absorver umidade do ar: ela incha, depois ela perde umidade para o ar, contraindose, então está em movimentação. Só que a epóxi não vai acompanhar esse movimento. Então chega um momento que a cola de epóxi vai criar uma tensão e a madeira vai quebrar de novo em volta dela. Nesse caso, você tem que pensar "vou usar uma cola baseada em uma cola proteica ou baseada em amido, que é um carboidrato, porque essas colas teriam essa movimentação adequada". Cada momento

\footnotetext{
${ }^{5}$ Cesare Brandi (1906-1988) é um restaurador e professor universitário italiano, cujas produções são associadas à história da arte, à estética e aos estudos do patrimônio. Um dos responsáveis pela fundação do Istituto Centrale del Restauro em Roma no final da década de 1930, Brandi também é autor da obra "Teoria da Restauração", editado no Brasil pela Ateliê Editorial.
} 
que o restaurador vai usar um material diferente em uma obra de arte, ele tem que entender quais são as propriedades materiais dela. E quem melhor que a Química, não é? Para poder saber isso. [...] E a Química viria um pouco mais como uma Ciência central. Então todas as outras áreas vão "beber" da Química para aprender alguma coisa sobre ela. [...] O restaurador precisa ter aquele conhecimento básico pra interferir na obra de arte, mas ele não precisa ter um conhecimento total da Química. [...] Então, vai chegar momentos que talvez ele vai precisar de um químico quando a situação for um pouco além do alcance dele. Mas o interessante é que ele deve saber alguma coisa de Química porque se ele utilizar materiais inadequados, ele vai acabar causando um dano na obra.

Fonte: Entrevista organizada pelos autores (2021).

Trazemos agora, cinco contribuições de diferentes licenciandos de Química no fórum do Moodle sobre a entrevista anterior. É importante ressaltar que selecionamos essas participações baseando-nos em sua representatividade. Assim, a partir da leitura de todas no fórum, percebemos alguns temas recorrentes tratados pelos estudantes. Esses cinco relatos transcritos a seguir representam esses temas mais recorrentes, visto que a opinião dos licenciandos sobre eles foi muito próxima, não havendo ideias discordantes.

Contribuição 1 - Ao assistir a entrevista, foi possível observar vários aspectos relevantes na integração entre a conservação/restauro do patrimônio e a Química/Ciência e, na minha opinião, um dos que mais me chamaram atenção foi a importância de se entender o material de cada obra de arte, já que o mesmo influencia não só na aparência das estruturas, mas também no seu processo de conservação e na ação do meio.

Contribuição 2 - A Química é uma ciência central, que se faz presente o tempo todo em nossas vidas. E é muito interessante perceber o quanto ela é fundamental para outros campos do conhecimento. Nós, alunos do curso de Química, raramente contextualizamos os conceitos que aprendemos com a Arte. [...] A maior parte das pessoas não imaginam a proximidade existente entre Química e Arte. e perceber a aplicação dos conhecimentos químicos para a restauração e conservação é bastante cativante e curioso.

Contribuição 3 - Um ponto muito importante para mim foi compreender a diferença entre conservação e restauração. Outro ponto foi entender que a Arte vai além da estética e da 
história, mesmo sendo uma estudante do curso de Química, eu nunca apreciei a Arte pensando nos materiais e na química deles. Ao ver a entrevista, comecei a olhar por um outro ângulo: os materiais são essenciais para a construção da obra de arte e que a escolha errada pode destruí-la.

Contribuição 4 - Algo que me chamou bastante a atenção logo de inicio foi a formação em Química do entrevistado. Eu pensei que restauração e conservação não era um espaço tão atuante dos químicos, no máximo algum artista que precisou se especializar para trabalhar nisso.

Contribuição 5 - Tenho por mim que levar o contexto artístico e relacionar com o material seja o ponto mais importante da entrevista. Me chamou mais ainda a atenção em saber que um simples material na pintura pode retratar o contexto histórico envolvido em uma época em que a obra foi feita. Por fim, penso que a abordagem desses temas dentro de uma sala de aula pode ser o "gancho" perfeito para a interdisciplinaridade.

A partir dos relatos, percebemos que os licenciandos além de desconhecer as áreas da conservação e da restauração, ainda não sabiam de suas peculiaridades e aproximações. Além disso, eles destacam a possibilidade de integrá-las aos conteúdos científicos, por meio da materialidade de cada obra. Salientamos a Contribuição 5, na qual o(a) licenciando(a) relacionou a entrevista com um contexto de sala de aula, mostrando uma possível integração entre diferentes áreas do conhecimento. Essa integração também foi apontada na Contribuição 4, cujo(a) autor(a) ressalta a formação do entrevistado e sua área de atuação, além da Contribuição 2 que denuncia a ausência de contextualizações dos conceitos da Química a partir da Arte. As discussões sobre os temas da entrevista continuaram em um encontro síncrono na plataforma Microsoft Teams e serão discutidos na seção a seguir.

\section{As discussões do encontro síncrono}

No encontro síncrono, ocorrido em 07 de outubro de 2020, foi proposta uma discussão de que conservar e restaurar a obra são ações complexas e distintas que envolvem diversas áreas do conhecimento e podem ir de encontro aos processos artísticos. Para exemplificar essa 


\section{OO DEVIR EDUCAÇÃO \\ ISSN: 2526-849X}

situação, os professores da disciplina compartilharam uma apresentação em Power Point com os estudantes com as imagens presentes nessa seção, como a Figura 5 que mostra a utilização de materiais biológicos como frutas, seguido por um poema no qual a autora relaciona a imagem a algumas palavras. Nesse caso, a deterioração proporciona a experiência de sentidos desejada pela artista. Desta forma, a atuação do profissional da Química na área do patrimônio cultural é uma intervenção ponderada por diversos fatores, dentre eles os aspectos históricos e artísticos da obra.

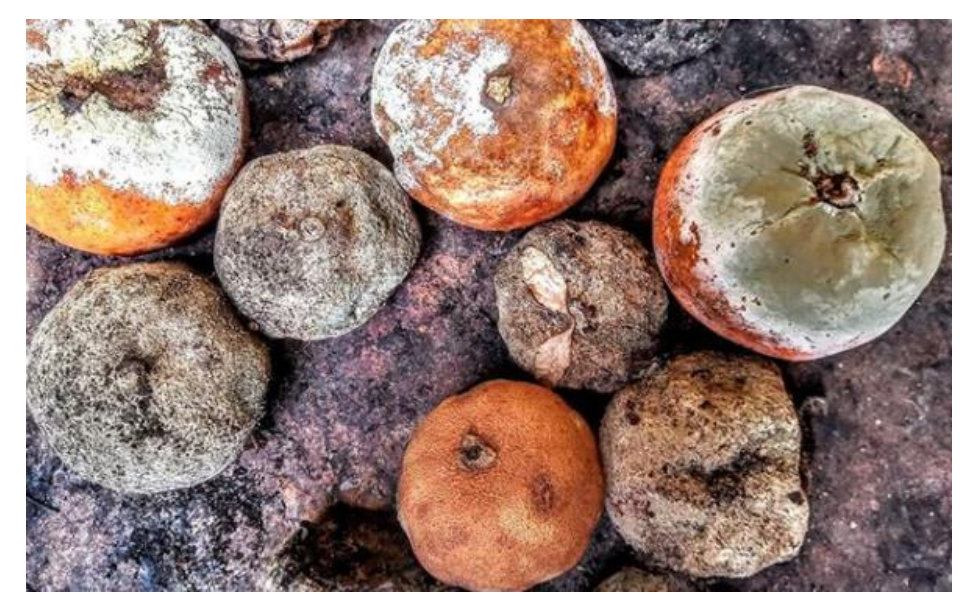


contágio $=$ contagem

opaco

frontal

chapado

plano

sem profundidade

monotônico

sem graça

previsível

entra um sai outro

substituível

boiada no pasto

fiéis do rebanho

coroação sem coração

Figura 5: Obra da artista brasileira Edith Derdyk ${ }^{6}$.

Fonte: retirado de https://www.instagram.com/edithderdyk/?hl=pt-br. Acesso em 23 de setembro de 2020.

No encontro, também foi apresentado o caso da obra Neither, da artista Doris Salcedo ${ }^{7}$ (Figura 6), presente no Instituto de Arte Contemporânea e Jardim Botânico Inhotim, situado na cidade de Brumadinho-MG, a 60 quilômetros da capital do estado. Formada por gesso e aço, que são materiais considerados quimicamente incompatíveis, visto que o gesso absorve água e oxida o ferro, mudando a cor do metal pelo processo de corrosão, a obra está exposta em uma galeria com controle de umidade e temperatura. Como não era o intuito da artista a alteração de coloração do ferro, a Química viria, atrelada à conservação e à restauração, impedir o aumento da corrosão (conservação) e retirar as áreas já deterioradas (restauração), retornando a obra ao seu estado original.

\footnotetext{
${ }^{6}$ Edith Derdyk (1955 - hoje) é uma pintora desenhista, designer gráfico e escritora, formada pela Fundação Alvares Penteado (FAAP), cujas produções podem ser acompanhadas por seu perfil no Instagram.

${ }^{7}$ Doris Salcedo (1958 - hoje) é uma artista colombiana contemporânea cujas instalações são produzidas a partir de objetos cotidianos e retratam a relação da humanidade com a perda, o luto e a violência.
} 


\section{OO DEVIR EDUCAÇÃO \\ ISSN: 2526-849X}

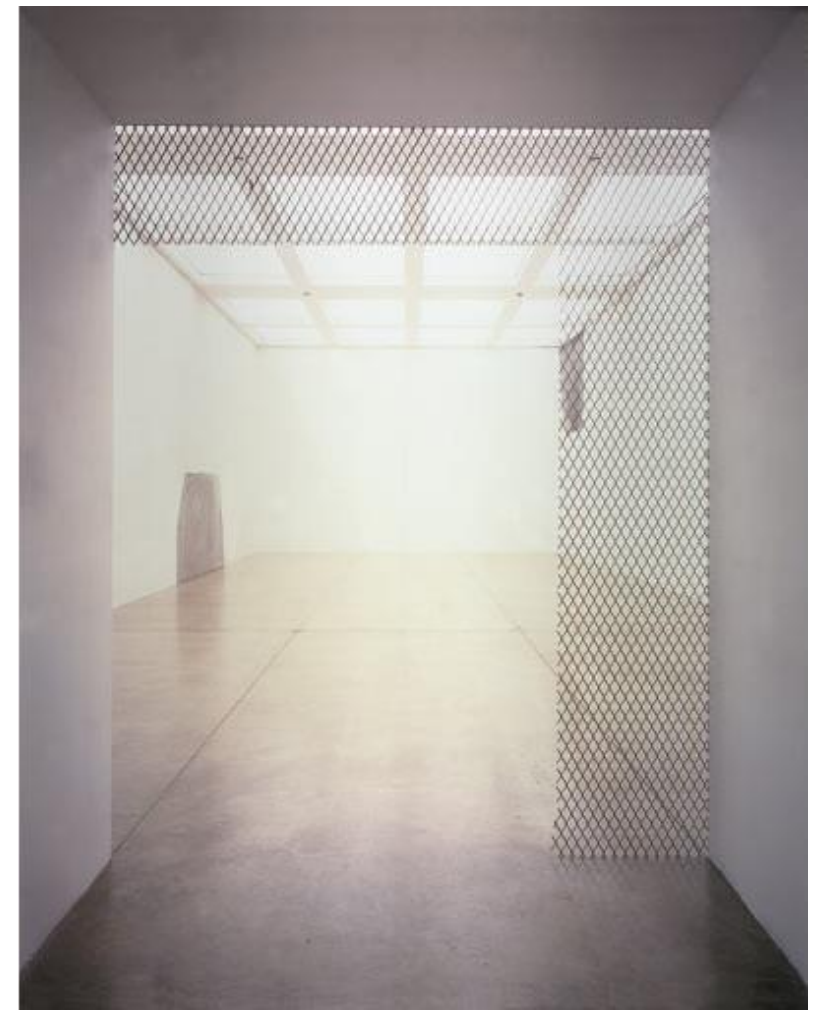

Figura 6: Neither. Doris Salcedo, placas de gesso e aço, 494 x 740 x 1500 cm, 2004.

Fonte: retirado de https://www.inhotim.org.br/inhotim/arte-contemporanea/obras/neither/. Acesso em 08 de dezembro de 2020.

Uma das licenciandas que já tinha ido ao Instituto Inhotim, relata sua experiência associando-a à entrevista do professor Dr. João Cura, conforme a transcrição a seguir.

Relato - Eu fui ao Inhotim umas duas vezes e ainda não cheguei a ver nem a metade. Mas vendo essa entrevista eu comecei a ver por uma outra perspectiva, principalmente em relação aos materiais que ele citou. Eu fiquei até assustada comigo mesma porque a gente que está estudando Química, a gente costuma enxergar as coisas, sabe? Em tudo, você vê Química. E quando eu fui lá, eu via só o aspecto histórico ou estético. Eu não parei para pensar muito nessa questão dos materiais. Vendo a entrevista, eu lembrei das vezes que eu fui lá e eu comecei a lembrar daqueles blocos da Tropicália [Figura 7] que ficam do lado de fora. Eu pensei que teve um esforço para fazer aqueles blocos, deixarem eles expostos. Depois da entrevista, eu comecei a enxergar por um outro ângulo. 


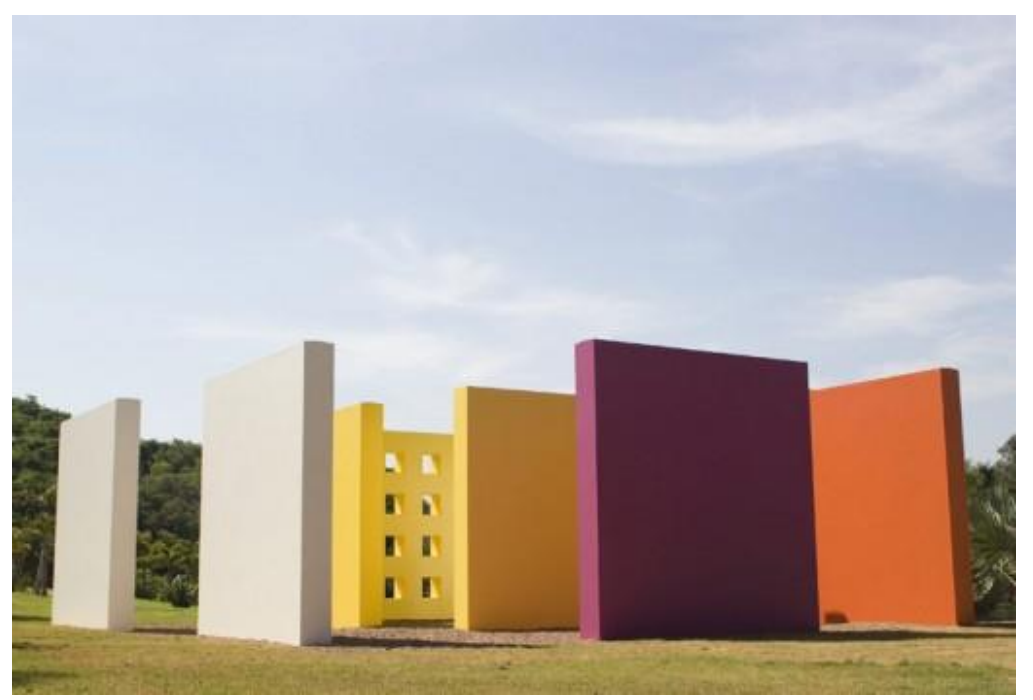

Figura 7: Invenção da Cor - Penetrável - MagicSquare \#5 - De Luxe. Hélio Oiticica ${ }^{8}$, obra in situ, 1977. Retirado de https://www.inhotim.org.br/inhotim/arte-contemporanea/obras/invencao-da-cor-penetravel-magicsquare-5-de-luxe/. Acesso em 08 de dezembro de 2020.

A partir do relato da aluna, foi destacado que a experiência artística está mais próxima de nós do que pensamos, podendo ser encontrada fora dos museus e galerias, mencionando a escultura do Leandro Gabriel na FaE (Faculdade de Educação) em aço corten e outros metais (Figura 2). Ampliando a discussão sobre os materiais das obras artísticas, foi explicado que o material selecionado pelo artista vai oxidando com o tempo e ficando com a coloração de ferrugem. A seleção dos materiais pelo artista dialoga com sua proposta estética/criativa e pode levar em conta os possíveis processos de deterioração e a forma de exibição. Por exemplo, o aço corten oxida apenas sua camada de fora, conservando por dentro sua estrutura metálica, mantendo a integridade material da obra. Esse material, denominado aço patinável, já foi utilizado anteriormente por outros artistas, como o mineiro Amilcar de Castro ${ }^{9}$ (Figura 8), citado na entrevista com o Dr. João Cura, cujas obras metálicas ficam expostas em áreas externas assim como a escultura de Leandro Gabriel.

\footnotetext{
${ }^{8}$ Hélio Oiticica $(1937$ - 1980) foi um artista plástico e performático brasileiro integrante da arte concreta, conhecido por seus penetráveis, espaços onde o público poderia interagir diretamente com a obra e passar por experiências sensoriais.

9 Amilcar de Castro (1920-2002) foi um artista plástico e designer mineiro integrante do Movimento Neoconcreto, propondo esculturas com cortes e dobraduras em materiais rígidos, como o aço corten e SAC.
} 


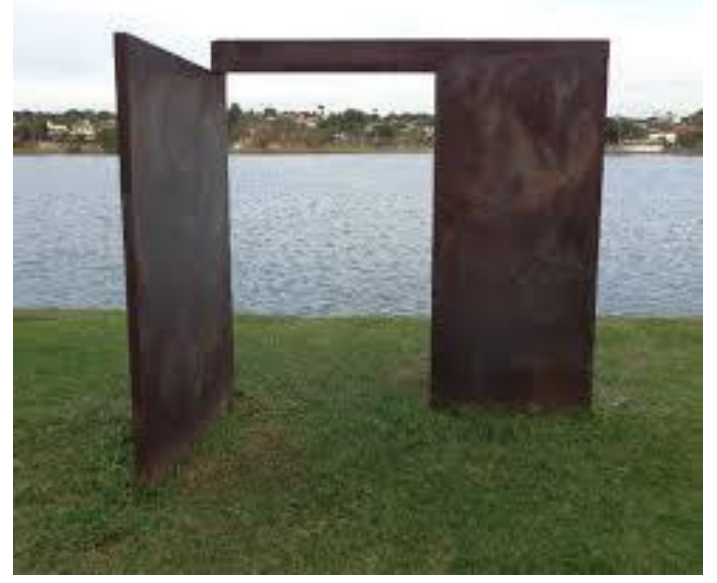

Figura 8: Amilcar de Castro. A Porta, Museu de Arte da Pampulha. Aço SAC.

Retirado de https://www.eba.ufmg.br/pos/sepoga/index.php/sepoga/sepoga15/paper/viewFile/11/1o. Acesso em 23 de setembro de 2020 .

Foi apresentado, então, o trabalho de Amilcar de Castro, em cujas obras, havia a utilização do material metálico "que tem a peculiaridade de enferrujar até um determinado ponto, a partir do qual sua oxidação cessa" (NAVES, 2011, p. 239). Para exemplificar o processo de escolha do material pelo artista, foi lido para os estudantes o seguinte trecho do livro "A forma difícil: ensaios sobre a arte brasileira", de Rodrigo Naves:

Amilcar de Castro costuma repetir que 'alumínio não tem caráter' e que por isso não o utiliza. Sua maleabilidade realmente torna-o disponível às mais variadas modulações. Falta-lhe uma tenacidade específica, que o conduzisse a ceder apenas a determinados arqueamentos e flexões, capazes de vergá-lo no ponto certo. Diferentemente do ferro, o alumínio - bem como muitos outros materiais - parece não sentir a passagem do tempo, e com isso repele os sedimentos que a idade acumula e que dão às coisas uma feição própria. Um presente contínuo acentua aquela disponibilidade absoluta, pois tudo está para acontecer pela primeira vez... e o caráter não se forma (NAVES, 2011, p.238-239).

A partir desse processo de deterioração das obras em metais, um aluno se lembrou de uma escultura presente no Instituto Inhotim, conforme o relato a seguir.

Relato: "Tem uma obra da queda de viga [Figura 9]. Eles fizeram um buraco, aí colocou o cimento. Quando o cimento estava molinho, eles jogaram com... tipo um guindaste, não sei, as vigas de metal. Essas vigas iam caindo no buraco e batendo, saía até fogo porque batia um metal no outro. O cimento secou e do jeito que o metal caiu, ele ficou e está exposto lá no Inhotim, foi feita em 2008. Tem até um vídeo no YouTube mostrando como ela foi feita. Ela está se deteriorando, então o artista que fez essa obra deve ter a intenção de deteriorar”. 


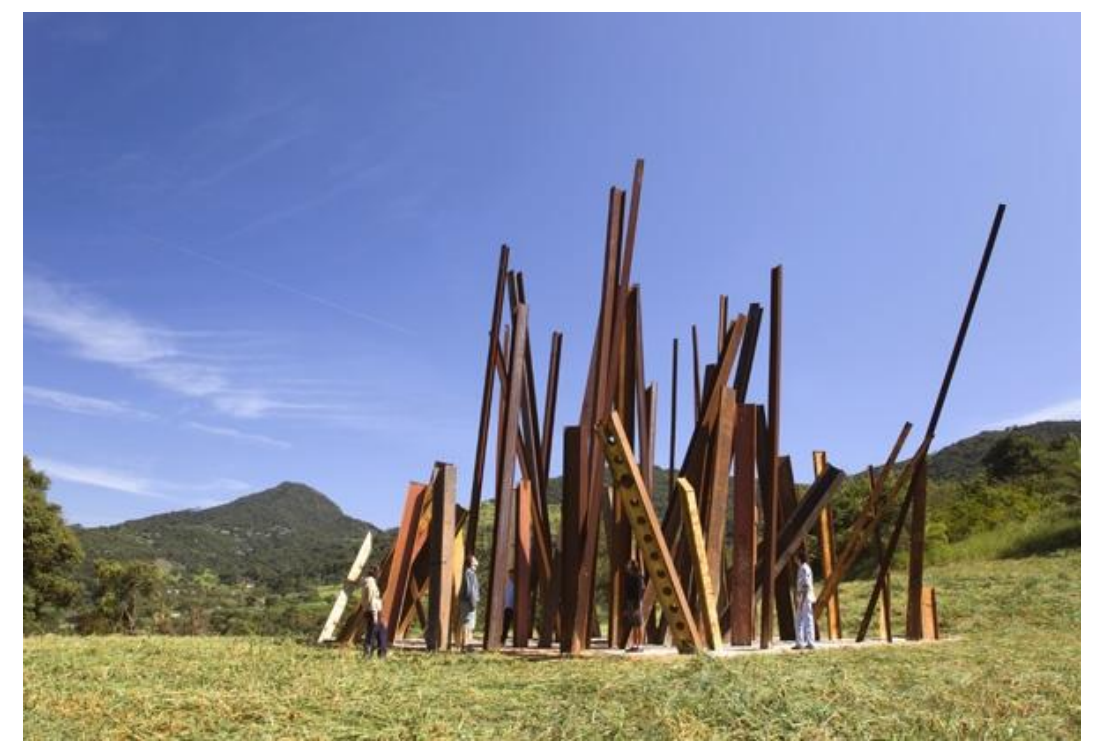

Figura 9: Chris Burden 10 "Beam Drop Inhotim 2008" - Foto: Eduardo Eckenfels. Retirado de https://www.inhotim.org.br/inhotim/arte-contemporanea/obras/beam-drop-inhotim-2008/. Acesso em 23 de setembro de 2020.

Foi explicado que cada obra tem especificidades e não foi feita, propriamente, para deteriorar. Por exemplo, o caso de Beam Drop Inhotim 2008 (Figura 9) trata-se de uma obra classificada como site-specific, ou seja, foi criada e planejada em um local específico, alterando-o e estabelecendo com ele uma relação intrínseca e interdependente (CASTILLO, 2008). Beam Drop Inhotim 2008 foi construída pelo artista estadunidense Chris Burden que

utilizou 71 vigas de ferro selecionadas em ferros velhos próximos ao Instituto. A performance, que durou cerca de 12 horas, foi realizada com um guindaste e uma grande equipe que seguia as orientações de Burden sobre como lançar as vigas de uma altura de 45 metros sobre uma piscina de cimento fresco. Aquilo que está diante de nossos olhos é o registro da performance de Burden (DIAS, 2016, p. 34).

Foi explicado aos estudantes que a obra presente no Inhotim se tratava, então, de o resultado de uma performance, por isso o registro em vídeo citado pelo aluno. A performance seria uma manifestação artística que destaca o fazer artístico no momento, como uma apresentação. É importante ressaltar que essa definição foi trazida apenas como uma forma de

\footnotetext{
${ }^{10}$ Chris Burden (1946-2015) foi um artista americano que trabalhou na performance e instalação, sendo um dos expoentes do movimento body art.
} 
introdução dos alunos às diversas poéticas e expressões artísticas, sendo que "nenhuma outra forma de expressão artística tem um programa tão ilimitado [quanto à performance], uma vez que cada performer cria sua própria definição ao longo de seu processo e modo de execução" (GOLDBERG, 2006, p. IX). Desta forma, o que estava em foco ali não eram apenas as vigas metálicas ou o cimento - a materialidade da obra - mas também o processo criativo no momento de queda das vigas metálicas.

Esses exemplos suscitados pelos estudantes colaboraram para o contato com as variadas formas de expressão artísticas, problematizando que nem sempre a conservação/restauração é o caminho, mas sim a compreensão dos processos criativos e da materialidade da obra. Destacou-se que o suporte da arte além de variado, pode inexistir, sendo imprescindível a responsabilidade da Química em dialogar com outras áreas. Os exemplos trazidos pelos estudantes em seus relatos comprovam seu interesse em investigar os fatores materiais das obras a partir de sua relevância patrimonial. Além disso, os processos de conservação e restauração são responsáveis apenas pela perpetuação da integridade material das produções, que foram elaboradas em um contexto cultural e histórico específico, que deve ser respeitado e analisado, assim como o processo criativo do artista.

\section{Considerações finais}

A partir das experiências apresentadas neste trabalho, percebemos que com a utilização das TIC foi alterado o modo como o conhecimento foi apresentado e discutido com os licenciandos no conjunto de atividades apresentado. Isso pode ser observado a partir das mudanças em seu planejamento presencial e remoto, o primeiro com a visita a algumas obras que faziam parte do cotidiano dos estudantes e o segundo a partir de uma entrevista, realizada com a utilização de softwares de coleta e gravação de imagens.

Notamos que as TIC possibilitaram a dinamicidade dos encontros síncronos, levando os estudantes a opinarem sobre as obras de arte, sua materialidade e suas experiências estéticas. Nesse sentido, destacamos que as percepções dos licenciandos foram permeadas tanto pelos fatores artísticos das obras quanto pelas percepções científicas, por exemplo, quando relatam a deterioração por corrosão da obra Beam Drop Inhotim 2018 (Figura 9). A 


\section{OO DEVIR EDUCAÇÃO \\ ISSN: 2526-849X}

partir desse encontro de saberes na fala dos licenciandos, observamos que eles relacionaram essas áreas do conhecimento.

Nas discussões síncronas, as TIC foram ferramentas que aproximaram os licenciandos das obras citadas nos relatos. A partir do momento que as imagens das produções artísticas foram compartilhadas pelo Microsoft Teams, o estudante não só pôde contextualizar o que era discutido pela turma, como também teve contato com a materialidade da obra, tão importante nos tópicos sobre conservação e restauração abordados.

Percebemos que a introdução das TIC no planejamento, assim como a transposição das atividades do formato presencial para o remoto, fez com que a atividade perdesse seu caráter investigativo. Presencialmente, os licenciandos, in loco, poderiam coletar imagens da obra do artista Leandro Gabriel para a investigação dos fenômenos de deterioração dos metais. A partir dessas discussões, haveria a introdução dos conhecimentos científicos atrelados à conservação e à restauração. No planejamento remoto, contudo, os estudantes foram convidados a verem uma entrevista, a qual já abordava o diálogo entre a Química e as Ciências do Patrimônio. Podemos apontar, então, que o planejamento remoto não conservou a perspectiva investigativa, mas foi dinamizado pelas TIC nos encontros síncronos. Apontamos, então, a potencialidade de estudos sobre a construção de perspectivas investigativas com a utilização integral de TIC, com foco no ensino remoto e à distância.

É importante ressaltar as diferentes TIC discutidas neste trabalho, selecionadas levando em conta suas potencialidades e visando uma maior acessibilidade dos licenciandos às informações e discussões. Destacamos o fórum do Moodle como um recurso de coleta de percepções dos estudantes sobre a conservação e a restauração de bens culturais, o Microsoft Teams como um "palco" de discussões e o OBS Studio como uma ferramenta de registro e produção de materiais. Em suma, destacamos que o potencial de cada TIC pôde ser discutido neste trabalho.

\section{Referências}

Revista Devir Educação, Lavras-MG. Edição Especial, p.90-117, Set./2021. 
AMARAL, Eliana; POLYDORO, Soely. Os desafios da mudança para o Ensino Remoto Emergencial na graduação na UNICAMP - Brasil. Linha Mestra, n. 41, p. 52-62, 2020. Disponível em: <http: http://lm.alb.org.br/index.php/lm/article/view/392>. Acesso em 19 de junho de 2021.

ANDIFES. Reitores fazem relatos sobre as experiências de ensino remoto em seminário da Andifes. Brasília, DF: Portal ANDIFES. Disponível em: https://bit.ly/2RfGfFG. Acesso em: 3 ago. 2020.

ARAÚJO, Sandra Cristina Marquez; SILVA, Rejane Maria Ghisolfi da. Tecnologias digitais na formação do professor de Química mediada pela construção de webquest. In: NERY, Belmayr Knopki; ZANON, Lenir Basso. (org.). Tecnologias de Informação e Comunicação na Prática Docente em Química e Ciências. 1 ed. Ijuí: Ed. Unijuí, 2016, p. 73-96.

ARRUDA, Eucidio P. Educação remota emergencial: elementos para políticas públicas na educação brasileira em tempos de Covid-19. EmRede - Revista de Educação a Distância, v. 7, n. $1, \quad$ p. 257-275, 2020. Disponível em: <http: https://www.aunirede.org.br/revista/index.php/emrede/article/view/621>. Acesso em 19 de junho de 2021.

BONI, Valdete; QUARESMA, Sílvia Jurema. Aprendendo a entrevistar: como fazer entrevistas em Ciências Sociais. Em Tese - Revista Eletrônica dos Pós-Graduandos em Sociologia Política da UFSC, v. 2, n. 1, p. 68-80, 2005. Disponível em: <http: https://periodicos.ufsc.br/index.php/emtese/article/view/18027>. Acesso em 15 de junho de 2021.

BRASIL. Decreto $\mathrm{n}^{\mathrm{o}}$ 9057, de 25 de maio de 2017. Regulamenta o art. 80 da Lei $\mathrm{n}^{\mathbf{o}}$ 9.394, de 20 de dezembro de 1996, que estabelece as diretrizes e bases da educação nacional. Diário Oficial da União, Poder Executivo, Brasília, DF, 26 mai. 2017. Seção 1, p. 3.

CASTILLO, Sonia Salcedo del. Cenário da arquitetura da arte. São Paulo: Martins Fontes, 2008.

CASTIONI, Remi; MELO, Adriana Almeida S. de M.; NASCIMENTO, Paulo Meyer; RAMOS, D. L. Universidades federais na pandemia da Covid-19: acesso discente à internet e ensino remoto emergencial. Ensaio: Avaliação e Políticas Públicas em Educação, v. 29, n. 111, p. 1-21, 2021. Disponível em <http: https://www.scielo.br/j/ensaio/a/53yPKgh7jK4sT8FGsYGn7cg/>. Acesso em 10 de junho de 2021.

DIAS, Paula Duarte Rachid. Comunicação e arte contemporânea: as obras site-specific do Inhotim. 2016. 47 p. Monografia (Graduação em Comunicação Social/Jornalismo) Universidade Federal do Rio de Janeiro - UFRJ, Escola de Comunicação - ECO, Rio de Janeiro, 2016. 
FIGUEIREDO JUNIOR, João Cura D'Ars. Química aplicada à conservação e restauração de bens culturais: uma introdução. Belo Horizonte: São Jerônimo, 2012.

GENTIL, Vicente. Corrosão. Rio de Janeiro: LTC, 2014.

GOLDBERG, RoseLee. A arte da performance: do futurismo ao presente. São Paulo: Martins Fontes, 2006.

HETKOWSKI, Tânia Maria. Mestrados profissionais em educação: políticas de implantação e desafios às perspectivas metodológicas. Plurais Revista Multidisciplinar, v. 01, n. 01, p. 1129, 2018. Disponível em: <http: https://www.revistas.uneb.br/index.php/plurais/article/view/2299>. Acesso em 15 de junho de 2021.

KENSKI, Vani Moreira. Educação e tecnologias: o novo ritmo da informação. Campinas: Papirus, 2012.

LAGO, Nicole Cecchele; TERRA, Stela Xavier; CATEN, Carla Schwengber Ten; RIBEIRO, José Luis Duarte. Ensino remoto emergencial: investigação dos fatores de aprendizado na educação superior. RIAEE - Revista Ibero-Americana de Estudos em Educação, v. 16, n. 2, p. 391-406, 2021. Disponível em < https://periodicos.fclar.unesp.br/iberoamericana/article/view/14439>. Acesso em 12 de junho de 2021.

NAVES, Rodrigo. A forma difícil: ensaios sobre arte brasileira. São Paulo: Companhia das Letras, 2011.

PASCUAL, Eva; PATIÑO, Mireia. O restauro de pintura: a técnica e a arte do restauro em pintura sobre tela explicados com rigor e clareza. Lisboa: Editorial Estampa, 2003.

UNIVERSIDADE FEDERAL DE MINAS GERAIS (UFMG). Conselho de Ensino, Pesquisa e Extensão. Resolução $\mathrm{N}^{\circ}$ 02/2020, de 9 de julho de 2020. Belo Horizonte: Universidade Federal de Minas Gerais, 2020. Disponível em <http: https://www2.ufmg.br/prograd/prograd/Pro-Reitoria-de-Graduacao/Publicacoes/ResolucoesComuns>. Acesso em 19 de julho de 2021.

VIVANCO, Georgina; GOROSTIAGA, Jorge. Cultura digital y diversidade: perspectivas de discursos de políticas TIC-Educación. Cadernos de Pesquisa - Fundação Carlos Chagas, v. 47, n. 165, p. 1016-1043, 2017. Disponível em <http: http://publicacoes.fcc.org.br/index.php/cp/article/view/4261>. Acesso em 20 de julho de 2021.

Recebido em: 26/06/21

Aprovado em: 19/07/21

Revista Devir Educação, Lavras-MG. Edição Especial, p.90-117, Set./2021. 